\title{
Quantitative and Qualitative Assessment of Adolescents' Future Time Perspective
}

\author{
Renato Gomes Carvalho ${ }^{1}$ \\ Universidade de Lisboa, Lisboa, \\ Portugal
}

\begin{abstract}
Developing perspectives concerning the future in adolescence has been associated with several adaptive behaviors in school context. However, a need to understand how these prospects are build remains. In this paper, two studies on adolescents' future time perspective (FTP) are presented, highlighting its connection to the present experience. Participants were adolescents, aged 14 to 18 . In the first study $(N=551)$, it is analyzed the factorial structure of a questionnaire designed to assess FTP in school context. A significant association of academic performance with FTP was found. In the second study $(N=11)$, through an analysis, based on Grounded Theory, to qualitative data derived from interviews, it was found that adolescents think considerably about their future, despite showing to be predominantly focused on career related dimensions. The influence on prospective thinking of both educational agents of the participation in multiple activities was also identified.
\end{abstract}

Keywords: time perspective, adolescents, schools, quantitative research, qualitative research

\section{Avaliação Quantitativa e Qualitativa das Perspectivas de Futuro dos Adolescentes}

\begin{abstract}
Resumo: O desenvolvimento de perspectivas temporais de futuro (PTF) na adolescência tem sido associado a comportamentos adaptativos em contexto escolar. Contudo, persiste a necessidade de compreensão de como essas PTF são construídas. Neste trabalho, apresentamos dois estudos sobre a PTF, destacando a sua ligação com a experiência presente. Os participantes foram adolescentes com idades entre 14 e 18 anos. No primeiro estudo $(N=551)$, analisamos a estrutura fatorial de um questionário construído para avaliar a PTF em contexto escolar. Identificamos uma associação significativa entre desempenho académico e PTF. No segundo estudo $(N=11)$, através de uma análise, fundada na Grounded Theory, de dados qualitativos decorrentes de entrevistas, verificamos que os adolescentes se preocupam com o seu futuro, referindo-se predominantemente a dimensões relacionadas com a carreira. Tais resultados apontam ainda para a influência que diferentes agentes educativos e a participação em múltiplas atividades têm no seu pensamento prospetivo.
\end{abstract}

Palavras-chave: perspectiva de tempo, adolescentes, escolas, pesquisa quantitativa, pesquisa qualitativa

\section{Evaluación Cuantitativa y Cualitativa de las Perspectivas de Futuro de los Adolescentes}

\begin{abstract}
Resumen: El desarrollo de perspectivas de futuro (PTF) en la adolescencia se asocia con varias conductas adaptativas en contexto escolar. Sin embargo, sigue existiendo la necesidad de comprender cómo se construyen estas PTF. En este trabajo se presentan dos estudios sobre la PTF, destacando su conexión con la experiencia presente. Los participantes fueron adolescentes de 14 hasta 18 años. En el primer estudio, se analiza la estructura factorial de los resultados de un cuestionario diseñado para evaluar la PTF en contexto escolar. Fue encontrada además una asociación significativa entre PTF y el rendimiento académico. En el segundo estudio, a través de un análisis basado en la Grounded Theory a datos cualitativos obtenidos de entrevistas, se encontró que los adolescentes se preocupan por su futuro, refiriéndose predominantemente a dimensiones relacionadas con la carrera. Estos resultados también apuntan hacia la influencia de los diferentes agentes educativos y de participación en múltiples actividades en su visión de futuro.
\end{abstract}

Palabras clave: perspectiva de tiempo, adolescentes, escuelas, investigación cuantitativa, investigación cualitativa

Adolescence corresponds to a period of human development in which a wide array of personal and social experiences contribute to deep adolescents' awareness about his/her uniqueness and to foresee the future, in the form of different representations, goals, and projects that are created.

\footnotetext{
1 Correspondence address:

Renato Gomes Carvalho. Centro de Investigação em Ciência Psicológica, Faculdade de Psicologia, Universidade de Lisboa. Alameda da Universidade. CEP 1649-013. Lisboa, Portugal. E-mail: renatoggc@gmail.com
}

Furthermore, the emerging capacity of abstract reasoning and other neurodevelopmental phenomena provide the conditions for the ability to think in a more complex manner, and to be oriented towards the future. In this sense, adolescence is a fundamental period for the development of career and life projects (Savickas, 2005) and also to the analysis of the personality characteristics involved in that process. Among these personality characteristics, future time perspective (FTP) has been receiving considerable attention in research. FTP is a cognitive-motivational variable, within 
time perspective theory, a conceptual framework aiming to analyze the way individuals give meaning to their experience according to different timeframes (Zimbardo \& Boyd, 1999). FTP involves an orientation towards the future, and the formulation of future objectives and projects concerning different life domains, such as career, leisure, family and social relationships, or the whole development as a person (Carvalho, Pocinho, \& Silva, 2010). As such, FTP expresses itself not only in extension (ie, the degree of projection into the future, which can result in a short- or long-term FTP), but also in content, that is, which particular goals are foreseen and how are they being formulated.

One of the main features that characterize FTP - which is focused in this study - is the individuals' ability to value present experience as relevant for the achievement of future goals. That is to say, FTP includes the anticipation of future objectives in present time, even if they are situated far in a distant future (Lens, Paixão, Herrera, \& Grobler, 2012; Lens \& Tsuzuki, 2007). In the school context, students with extended FTPs perceive their present behavior as more instrumental for the attainment of future goals (Simons, Vansteenkiste, Lens, \& Lacante, 2004), and this has a high-impact and positive motivational implications. In effect, research has been consistently showing a significant association between extended and elaborated FTPs concerning different life domains, on the one hand, and an array of adaptive behaviors, on the other. For instance, FTP relates to learning motivation and academic investment, to the delay of gratification, or to the use of efficient selfregulation strategies (Bembenutty \& Karabenick, 2004; de Bilde, Vansteenkiste, \& Lens, 2011; Peetsma, Hascher, \& van der Veen, 2005; Peetsma \& van der Veen, 2011; Simons et al., 2004). FTP also relates to career maturity (Janeiro, 2010; Paixão \& Silva, 2001; Walker \& Tracey, 2012), to lower likelihood of engagement in risk behaviors (Carvalho et al., 2010; Lens et al., 2012), and to social integration, including social engagement and participation in activities (Carvalho, 2012).

The ability to define personal future goals and projects, and to value present experience for their attainment, is therefore a personality characteristic that contributes for students' successful pathways at school. Nevertheless, as Lens et al. (2012) put it in a recent review, it is still necessary further understanding of the FTP importance in specific developmental periods, such as adolescence, when educational experiences are especially significant and important vocational decisions are taken. Moreover, it is important not only to know what are adolescents' main perspectives concerning the future, but also to understand how the connection between present experience and future goals is done - which experiences in the present are relevant for the way students define goals and perspectives, and take decisions. It is within this framework that, in this paper, adolescents' FTP in school context is analyzed, particularly at the level of the specific dimensions that can characterize their thinking about the future. That is, which aspects of the present reality are related to the way students look at the future. In Study 1 (S1), a factorial analysis to an instrument aiming to assess adolescents' FTP in school context is presented, in order (1) to identify the underlying factorial structure, reflecting specific FTP dimensions beyond the overall measure, and (2) to assess potential differences in FTP according to several socio-demographic and school achievement variables. In Study 2 (S2), through a qualitative strategy, emerging issues when students talk about their future are explored. The development of qualitative studies seems to be especially useful, given the preponderance of quantitative techniques, such as self-report surveys, in the research involving FTP with adolescents (Mello et al., 2009).

\section{Method - Study 1}

The assessment of individuals' FTP has been performed through different instruments that frequently are focused in global measures and used across different contexts, not taking into consideration the specificities of each one of those contexts. In fact, more attention should be given to FTP in different life domains and considering a broader range of participants, for instance at age or level of education (Lens et al., 2012). In this exploratory study it is analyzed an instrument aiming to assess an overall FTP, as well as potential specific dimensions of it. Moreover, this is an instrument focusing a specific population (adolescents) and a particular context (school). The effects of gender, age, area of residence, socioeconomic status (SES), and school success in FTP are also analyzed. The hypotheses were the following: (h1) there is a latent structure in the QFTP results, so different dimensions beyond the overall measure are expected; (h2) SES is positively associated to FTP; (h3) school success is positively associated to FTP (Carvalho, 2012). No hypotheses concerning gender and age were formulated, given the mixed findings in the literature (Mello \& Worrell, 2006).

\section{Participants}

The sample consisted in 551 Portuguese adolescents, mostly males $(N=310,56 \%)$, aged from 14 to 18 $\left(M_{\text {age }}=16, S D=1.4\right)$, and mostly living in rural areas $(N=423,77 \%)$. The majority of the participants were at 9th grade (the final grade of the basic educational level; $N=323,59 \%)$ and the remaining were at secondary level. The majority of the students had no retentions in their schooling $(N=310,56 \%)$, although their grades mean was low (in a $0-20$ scale; $M_{\text {grades }}=12.7, S D=2.4$ ). Considering SES, which was identified by considering parental education, students' majority were integrated in low $(N=249,45 \%)$ and medium-low SES $(N=178,32 \%)$ family environments. 


\section{Instruments}

Questionnaire of Future Time Perspective - QFTP (Carvalho, 2012). QFTP consists of 26 items with a Likertstyle scale with five possible answers (from Doesn't apply at all to me to Totally applies to me). These items were formulated to assess the degree of orientation towards the future, the valorization and integration of present experience as important to the future, and the existence of plans or projects concerning the future in different domains such as career, leisure, and interpersonal relationships. Items are presented in the Results section, since the analysis of this instrument is a specific goal of S1. This instrument was originally created as a one-dimensional measure to assess students' FTP, based in a set of relevant dimensions that characterize this construct (Carvalho, 2012).

\section{Procedure}

Data collection. QFTP (paper and pencil version) was collectively administered to students during a 45 minutes class, after adolescents' and their parents' informed consent. The booking of the data collection session was defined in agreement with each school directive board and with the teacher responsible for each class. The collected data was afterwards codified and inserted into a SPSS database.

Data analysis. In order to identify the latent factors of the QFTP, an exploratory factorial analysis (EFA) through principal axis analysis, with varimax rotation, was performed. The criterion for factor extraction was an Eingenvalue higher than 1 (Kaiser's criterion). Data were validated, concerning their eligibility for FA, through Kaiser-Meyer-Olkin measure, and Bartlett's test of sphericity. To the analysis of the school and socio-demographic variables effects on QFTP results performed afterwards, ANOVAs were used, after confirmation of the respective assumptions. Tukey test was chosen for post-hoc analyses.

\section{Ethical Considerations}

In this study, as well in S2, the ethical aspects of research involving human beings were met: students' and their parents' informed consent has been obtained, confidentiality in data treatment and analysis has been assured, and a preliminary analysis of the study has been done to determine its potential risks and benefits.

\section{Results}

\section{Factorial Analysis of the QFTP}

Results confirm data eligibility for FA, since the KaiserMeyer-Olkin measure didn't indicate sample inadequacy for FA $(\mathrm{KMO}=.854, p<.001)$ and Bartlett's Test of Sphericity showed sufficiently strong correlations among the items $\left[\chi_{(323)}^{2}=4162.37, p<.001\right]$. Six factors were identified, explaining about $55 \%$ of the variability. A correlation item $\mathrm{x}$ factor of at least.30 was considered as the inclusion criterion of an item in a given factor. In the case of the items with several relevant loadings, the inclusion was driven by the better adequacy of the item content to the factor content. The matrix of correlations of each item with each one of the six factors, after rotation, is presented in Table 1.

Considering the items content, there is one first emerging factor that explains most of the variability, which was named Concern and valorization of experience (items 3, 8, 10, 11, 15, 16, 22, 23; Cronbach's $\alpha=.86$ ). It reflects the degree in which adolescents are concerned and think about the future and with its planning, as well as the value they place in their present experience as important for their future, including investment in learning, the quality of interpersonal relationships, and skills and personal development. The second factor, Planning and personal development (items 5, 9, 14, 17, 26; $\alpha=.73$ ), involves the degree in which adolescents are committed to planning, and value their personal development. The third factor, Friendships and future activities (items 2, 18, $19,20,24 ; \alpha=.72$ ), relates to the valuing of activities and relationships with others as important for the future. The fourth factor, named Valorization of education for the future (items $1,12,25 ; \alpha=.66$ ), corresponds to the degree in which students are engaged with educational activities and value present education for their future. The fifth factor, Leisure (items 4, 7, 13; $\alpha=.58$ ), relates to the participation and involvement in significant activities during free time. Finally, the sixth factor, Family relationships (items 6 and 21; $\alpha=.67$ ), involves the valorization of family relationships in the present and for the future. Given that F5 presents a low indicator of internal consistency, it won't be regarded in the results analyses. On the other hand, since F4 and F6 have a reduced number of items, which suggests improvements for the future, including increasing the number of items, there should be some caution in the analysis of the results related to them. In Table 2 the correlation coefficients of the factors with the overall measure are presented, as well as among the six factors.

\section{Effects of Socio-Demographic Variables and School Achievement in FTP}

Regarding the effects of socio-demographic variables in QFTP results, as presented in Table 3, there are no major significant differences according to gender and area of residence, with two exceptions: females score higher in the Family dimension $\left[F_{(1,550)}=4.04, p<.05\right.$, $\left.\eta^{2}=.01\right]$, and in urban areas Friendships and activities are more valued, $\left[F_{(1,550)}=7.89, p=.007, \eta^{2}=.01\right]$. Nonetheless, the magnitude of these effects is low. With respect to age, significant differences occur for Concern and valorization of experience $\left[F_{(4,550)}=2.13, p<.05\right.$, $\left.\eta^{2}=.02\right]$, and Valorization of education, $\left[F_{(4,550)}=2.74\right.$, $\left.p<.05, \eta^{2}=.02\right]$. In both cases, post-hoc analysis shows 
Table 1

QFTP Items, Correlations of the Items With the Total Measure, and Rotated Loadings Matrix of Each Item With Each One of the Identified Factors

\begin{tabular}{|c|c|c|c|c|c|c|c|}
\hline \multirow{2}{*}{ QFTP items } & \multirow{3}{*}{$r_{\text {Item-Total }}$} & \multicolumn{6}{|c|}{ Identified factors (Eingenvalues $>1$ ) } \\
\hline & & 1 & 2 & 3 & 4 & 5 & 6 \\
\hline Amount of variability explained by the factor $(\%)$ & & 23.01 & 9.61 & 7.58 & 5.92 & 4.54 & 4.20 \\
\hline 1. What I do in school is very important for my life & .462 & .096 & .380 & .101 & .421 & -.08 & .184 \\
\hline 2. The way I relate to my friends is very important to me & .395 & .124 & .059 & .387 & .112 & -.01 & .234 \\
\hline 3. It doesn't matter what I'm learning in school this year & .541 & .473 & .147 & .047 & .358 & .104 & -.004 \\
\hline 4. I have amusing things to do in my free time & .346 & -.010 & .060 & .247 & -.02 & .549 & .164 \\
\hline 5. I'm very interested in what I'll be in the future as a human being & .577 & .188 & .665 & .108 & .175 & .006 & .228 \\
\hline 6. I like to maintain connections to my family & .477 & .177 & .099 & .121 & .142 & .146 & .732 \\
\hline 7. I don't know what to do in my free time & .378 & .199 & .018 & .043 & -.01 & .705 & .053 \\
\hline 8. In the future, the relationship I'll have with my family won't be important & .526 & .608 & .115 & .038 & -.06 & .143 & .216 \\
\hline 9. I hope to explore my capacities and talents in my future lifetime & .481 & .112 & .415 & .186 & .300 & .046 & .080 \\
\hline 10. It doesn't matter the kind of relationships I have with my relatives & .570 & .664 & .135 & .038 & -.02 & .090 & .265 \\
\hline 11. I'm not worried about the life I'll have in a few years & .417 & .437 & .000 & .088 & .067 & .079 & -.006 \\
\hline 12. I like the things I learn in school & .406 & .111 & .195 & -.01 & .718 & -.03 & .076 \\
\hline 13. In a few years, I won't know how to occupy my free time & .295 & .237 & .041 & -.08 & .002 & .433 & -.068 \\
\hline 14. I think it is very important to develop my abilities now & .578 & .221 & .427 & .190 & .437 & .063 & .010 \\
\hline 15. The things I do in school are of little importance for me & .478 & .436 & .046 & -.02 & .333 & .182 & -.033 \\
\hline 16. I'm not worried about developing my capacities and talents & .448 & .512 & .011 & .038 & .111 & .081 & .031 \\
\hline 17. I usually think about my future as a student or as a worker & .530 & .136 & .682 & .245 & .089 & .000 & -.021 \\
\hline $\begin{array}{l}\text { 18. I like to think about what I'll do when I'll have holidays and free days in } \\
\text { the future }\end{array}$ & .481 & .045 & .304 & .559 & -.05 & .138 & .128 \\
\hline 19. I usually think about the friends I'll keep in the future & .444 & .105 & .109 & .702 & .044 & -.02 & .038 \\
\hline 20. In the future, what I'll do in my free time will be very important for me & .452 & .036 & .170 & .688 & .044 & .100 & .030 \\
\hline 21. The way I relate to my relatives has an important role in my future & .536 & .243 & .171 & .378 & .057 & -.02 & .515 \\
\hline $\begin{array}{l}\text { 22. I know that, in a few years, whether I'll be studying or working, my } \\
\text { education won't be important }\end{array}$ & .505 & .606 & .119 & .033 & .095 & -.04 & .085 \\
\hline $\begin{array}{l}\text { 23. When I think about the future, I don't think that it would be important the } \\
\text { kind of person I'll be }\end{array}$ & .527 & .641 & .107 & .121 & .066 & -.03 & .028 \\
\hline 24. The way I occupy my free time makes me learn important things & .412 & -.036 & .226 & .380 & .117 & .352 & .012 \\
\hline 25. My education today has a great value for my future job & .582 & .205 & .424 & .238 & .379 & -.04 & .186 \\
\hline 26. I'm already thinking and planning what I'm going to do after this school & .377 & -.008 & .481 & .097 & .061 & .169 & .000 \\
\hline
\end{tabular}
year ends

Note. The correlations $r_{\text {item-total measure }}$ are all significant at $\alpha=.01$. The correlations that were considered for the inclusion of each item in each factor are signaled in bold. Cronbach's $\alpha$ of the total measure: .854 .

Table 2

Pearson Correlation Coefficients Among the Factors and of These With the Total Measure

\begin{tabular}{lcccccc}
\hline & F1 & F2 & F3 & F4 & F5 & F6 \\
\hline F1 - Concern & & & & & & \\
F2 - Planning & .334 & & & & & \\
F3 - Friendships & .210 & .442 & & & & \\
F4 - Val. Education & .353 & .593 & .304 & & & \\
F5 - Leisure & .281 & .172 & .223 & .011 & & \\
F6 - Family & .356 & .320 & .403 & .358 & .170 & \\
Total QFTP & .778 & .716 & .638 & .624 & .455 & .584 \\
\hline
\end{tabular}

Note. All coefficients are significant at .01 level, except for the correlation $\mathrm{F} 5 \mathrm{xF} 4$, which is not significant. that it is the youngest group (14-year-olds) that scores significantly higher. Finally, for SES, there are differences in the Friendships and activities dimension $\left[F_{(3,550)}=2.92\right.$, $\left.p<.05, \eta^{2}=.02\right]$, as well as in Valorization of education $\left[F_{(3,550)}=2.22, p<.05, \eta^{2}=.02\right]$. It is the lowest SES group that distinguishes mostly from the remaining groups, with a lower mean in Friendships and activities, and a higher mean in valuing education.

In relation to the indicators of academic performance, a wider set of significant results is observed. An association of grades (GPA) with the global measure occurs, $\left[F_{(2,549)}=24.44\right.$, $\left.p<.001, \eta^{2}=.08\right]$, as well as with other dimensions such as: Planning and personal development $\left[F_{(2,549)}=26.68, p<.001\right.$, 
$\left.\eta^{2}=.07\right]$, Valorization of education $\left[F_{(2,549)}=20.71, p<.001\right.$, $\left.\eta^{2}=.07\right]$, and Concern and valorization of experience $\left[F_{(2,549)}\right.$ $\left.=18.77, p<.001, \eta^{2}=.06\right]$. Post-hoc analyses show that all groups differ from each other, with the exception of Concern and valorization of experience, in which it is the first group (lower grades) that stands out, with significantly lower results. There is, therefore, a pattern according to which the higher the grades, the higher the QFTP scores. School achievement shows to be related to a wider FTP, to more concern and planning about the future, and to a valorization of present experience for future success. This pattern is corroborated considering retentions, since students with no retentions score significantly higher in almost every dimensions: Total FTP, $\left[F_{(1,550)}=34.88, p<.001, \eta^{2}=.06\right]$, Concern and valorization of present experience $\left[F_{(1,550)}=31.48, p<\right.$ $\left..001, \eta^{2}=.05\right]$, Planning and personal development $\left[F_{(1,550)}\right.$ $\left.=26.80, p<.001, \eta^{2}=.05\right]$, Valorization of education $\left[F_{(1,550)}\right.$ $\left.=11.51, p=.001, \eta^{2}=.02\right]$, Friendships and future activities $\left[F_{(1,550)}=6.34, p<.05, \eta^{2}=.01\right]$, and Family $\left[F_{(1,550)}=7.04\right.$, $\left.p=.008, \eta^{2}=.01\right]$.

\section{Discussion}

Factorial analysis puts in evidence six dimensions beyond the overall measure reflecting that, as hypothesized (h1), the notion that FTP expresses itself in different ways and across distinct domains. That is, beyond the global measure, there are specific dimensions that contribute to it. These particular aspects of FTP are of great importance since they allow a more detailed understanding about how students organize their thoughts respecting the relationship between present activities and future goals. For instance, considering the several socio-demographic and school related variables that were included in S1, it was possible to verify that, despite there were no significant differences in a one-dimensional measure of FTP (Total FTP) among the groups, differences in some of the specific domains occurred. That was the case for girls, who attributed a higher value to family relationships, and for students living in urban areas, scoring higher in the friendships and activities dimension. Respectively, these results give support to previous research (Marttinen \& Salmela-Aro, 2012), and

Table 3

Means and Standard Deviations of QFTP Results According to Different School and Socio-Demographic Variables $(N=551)$

\begin{tabular}{|c|c|c|c|c|c|c|c|c|}
\hline \multirow{2}{*}{ Variable } & \multirow{2}{*}{$n$} & Total FTP & F1 - Concern & F2 - Planning & F3 - Friends & F4 - Val Educa & F5 - Leisure & F6 - Family \\
\hline & & $M(S D)$ & $M(S D)$ & $M(S D)$ & $M(S D)$ & $M(S D)$ & $M(S D)$ & $M(S D)$ \\
\hline \multicolumn{9}{|l|}{ Area } \\
\hline Rural & 423 & $4.03(.46)$ & $4.12(.73)$ & $4.11(.62)$ & $3.91(.66)^{*}$ & $3.80(.69)$ & $3.92(.75)$ & $4.29(.75)$ \\
\hline Urban & 128 & $4.10(.43)$ & $4.11(.62)$ & $4.23(.61)$ & $4.08(.62)^{*}$ & $3.89(.60)$ & $3.94(.78)$ & $4.31(.75)$ \\
\hline \multicolumn{9}{|l|}{ Gender } \\
\hline Male & 310 & $4.03(.46)$ & 4.09 (.69) & $4.10(.63)$ & $3.93(.64)$ & $3.83(.67)$ & $3.94(.78)$ & $4.24(.79)^{*}$ \\
\hline Female & 241 & $4.07(.45)$ & $4.15(.72)$ & $4.18(.61)$ & $3.97(.68)$ & $3.82(.68)$ & $3.91(.74)$ & $4.37(.71)^{*}$ \\
\hline \multicolumn{9}{|l|}{ Age } \\
\hline 14 & 121 & $4.14(.42)$ & $4.28(.59)^{*}$ & $4.24(.59)$ & $3.98(.67)$ & $3.96(.60)^{*}$ & $3.85(.75)$ & $4.41(.67)$ \\
\hline 15 & 153 & $4.03(.48)$ & $4.13(.73)$ & $4.14(.60)$ & $3.89(.68)$ & $3.82(.65)$ & $3.96(.79)$ & $4.23(.82)$ \\
\hline 16 & 115 & $3.98(.47)$ & $4.08(.71)$ & $4.01(.65)$ & $3.86(.72)$ & $3.69(.70)^{*}$ & $3.98(.73)$ & $4.29(.74)$ \\
\hline 17 & 78 & $3.99(.48)$ & $3.97(.76)^{*}$ & $4.13(.62)$ & $3.98(.65)$ & $3.89(.74)$ & $3.85(.79)$ & $4.18(.78)$ \\
\hline 18 & 84 & $4.06(.41)$ & $4.04(.71)$ & $4.18(.64)$ & $4.07(.50)$ & $3.78(.70)$ & $3.97(.73)$ & $4.34(.75)$ \\
\hline \multicolumn{9}{|l|}{ SES } \\
\hline Low & 249 & $4.03(.45)$ & $4.12(.73)$ & $4.11(.62)$ & $3.86(.65)^{*}$ & $3.88(.66)^{*}$ & $3.87(.78)$ & $4.34(.73)$ \\
\hline M-Low & 178 & $4.09(.47)$ & $4.16(.64)$ & $4.17(.63)$ & $4.03(.67)$ & $3.86(.64)$ & 3.99 (.69) & $4.28(.77)$ \\
\hline Medium & 95 & $4.01(.46)$ & $4.05(.74)$ & $4.13(.61)$ & $4.03(.64)$ & $3.65(.74)$ & $3.92(.83)$ & $4.21(.77)$ \\
\hline High & 29 & $4.02(.50)$ & 4.05 (.69) & $4.23(.62)$ & $3.89(.72)$ & $3.71(.73)$ & $3.99(.66)$ & $4.25(.77)$ \\
\hline \multicolumn{9}{|l|}{ Grades } \\
\hline Low & 275 & $3.92(.48)^{*}$ & $3.94(.78)^{*}$ & $3.97(.66)^{*}$ & $3.88(.68)$ & $3.67(.66)^{*}$ & $3.89(.75)$ & $4.26(.75)$ \\
\hline Medium & 121 & $4.09(.39)^{*}$ & $4.19(.58)^{*}$ & $4.17(.58)^{*}$ & $3.97(.59)$ & $3.85(.65)^{*}$ & $3.98(.72)$ & $4.26(.77)$ \\
\hline High & 154 & $4.23(.41)^{*}$ & $4.35(.56)^{*}$ & $4.41(.48)^{*}$ & $4.04(.66)$ & $4.09(.65)^{*}$ & $3.95(.81)$ & $4.38(.76)$ \\
\hline \multicolumn{9}{|l|}{ Retentions } \\
\hline No & 310 & $4.14(.42)^{*}$ & $4.26(.62)^{*}$ & $4.25(.57)^{*}$ & $4.01(.66)^{*}$ & $3.91(.67)^{*}$ & $3.96(.76)^{*}$ & $4.37(.73)^{*}$ \\
\hline Yes & 241 & $3.92(.47)^{*}$ & $3.93(.76)^{*}$ & $3.98(.65)^{*}$ & $3.86(.66)^{*}$ & $3.72(.67)^{*}$ & $3.88(.77)^{*}$ & $4.20(.79)^{*}$ \\
\hline
\end{tabular}

Note. F1 - Concern and valorization of experience; F2 - Planning and personal development; F3 - Friendships and future activities; F4 - Valorization of education; F5 - Leisure; F6 - Familiy relationships. SES - Socioeconomic status. No interaction effects were found between these independent variables. Cases in which significant differences were found are marked with an asterisk $(*)$. 
may reflect an educational effect of girls upbringing; on the other side, they may reflect the frequent existence of a wider access to social, cultural, and economic resources in cities than in rural areas. Nevertheless, there was not found a wide gender-related effect on FTP, which goes along with previous research, in which no consistent findings have arisen (Mello $\&$ Worrell, 2006). Concerning age, it is relevant to underline that 14-year-old adolescents are more concerned about, and value more, the role of education for their future than their older counterparts. This may reflect the fact that they are all at 9th grade, which corresponds to the end of mandatory school and a major transition point in their academic trajectories. It is also significant that low-SES students have registered lower scores in the friendships and activities dimension, which may suggest difficulties in getting access to social networks and resources (Carvalho \& Novo, 2012). Nevertheless, it is as well remarkable that these students look to education as having an important role for their future life. Results confirm thus partially h2, given that significant SES-related differences occurred for only two dimensions. Finally, taking into account the indicators of school success, this study replicates the results obtained in previously mentioned studies with similar populations (Carvalho et al., 2010; Peetsma \& van der Veen, 2011), by associating FTP to better indicators of achievement. Hypothesis 3 was therefore confirmed. In fact, the ability to conceive future goals and to give structure to the future, reflecting FTP, is consistently related to school success, expressed for instance in grades and in the absence of retentions.

\section{Method - Study 2}

By emphasizing the association of FTP with school success, results in S1 encourage a deepened understanding of the factors that relate to the way students think about their future. In S2, a qualitative analysis to students' discourses about the future is performed, with the intention to identify emerging contents and to understand how the experience at school (activities and relationships) may influence their prospective thinking.

\section{Participants}

Sample consisted in 11 students ( 6 male, 5 female) that were participating in a career education program at the end of the 9th grade in a rural school, and offered themselves to be interviewed. This program was being implemented in a noncurricular course of students' weekly schedule. Ages ranged from 14 to $18\left(M_{\text {age }}=16 ; S D=1.5\right)$, with the most frequent categories being 15 and 14 year-olds (4 and 3 students respectively), and the least frequent 16 and 17-year-olds (one student per category). Concerning SES, the sample was homogeneous at medium-low SES, given that students' parents' highest level of academic qualifications was mandatory school.

\section{Instrument}

Data collection was performed through a semi-structured interview, with a script that was purposely created for this research. The interview script included one set of previously defined ten questions, which should be managed in a flexible manner depending on the progress of the interaction process. Some examples include "In your view, how are the things you presently do at school, related to what you'll do after the 9th grade?"; "Presently, who are the most important persons for your future?", "When you think about the future, what are the things that most matter to you?"; "How do you see yourself in the future?".

\section{Procedure}

Data collection. Students were told in class context that a research on how adolescents look at their future was being done, and that those interested in participate should enroll for a session. After defining a short list of eleven students that enrolled voluntarily, and obtaining informed consent from students and their parents, individual sessions were booked. In each session, a protocol was used in order to introduce the study. Participants were also told that they were not at a test (i.e., there were no correct or wrong answers), but at an informal interaction in which we would be talking about their thoughts about the future. Sessions took place in the office of the school counseling services and took about 30 to 45 minutes each. The interviews, which were performed by the author, were audio recorded, and afterwards transcribed.

Data analysis. The analytical strategy for this study was informed by Grounded Theory approach to qualitative data analysis (Strauss \& Corbin, 1990). This strategy includes a systematic examination of patterns in data in order to identify emergent themes, which were given meaningful titles. The codification of data involved a selective strategy, since the intention was to identify main categories and subcategories, in a hierarchical manner.

\section{Results}

In this section, the two major content categories that emerged from data analysis are presented, namely students' most referred life domains, in relation to which they develop future perspectives, as well as the connection between present experience and future life.

\section{Perspectives Concerning Different Life Domains}

It is noticeable that, despite all students think about their future at the end of 9th grade, there is considerable individual variability in the way those thoughts are structured. While some students consider the future with a high degree of complexity, linking different areas and having already clearer images about what they can/will do, others present dispersed images concerning their future. Nevertheless, there is an agreement about the importance of setting personal goals, 
both for short and extended timeframes, that is, data put in evidence the extension of students' FTP. An acknowledgment of the importance of education for greater employability also exists. As a 14-year-old female student puts it, "... because it is increasingly hard to find a job with a low qualification, such as 9 th grade (...) If you go to a company looking for a job, they will choose the person with better qualifications". Within this first category, it is also important to mention students' references to different domains of life, namely family or interpersonal, and career. The latter, though, is clearly the most mentioned by the students, as they seem to have developed a more accessible attitude towards the academic and professional domain. Although students mention the future in an optimistic manner, for instance as an opportunity for personal fulfillment and life improvement, they hardly make references concerning their overall development as persons or their leisure activities. For instance, about what matters most when thinking about the future, answers focused predominantly "Having a good job... with a nice salary" (14-year-old boy); "Friendships, to whom I'm going to relate to... having a house and a car... and a good profession" (14-year-old girl); "Having my family and a job to sustain it" (16-year-old boy); "To get a job... and start a family" (15-year-old girl).

\section{The Importance of Present Experience for Future Life}

Participating in relevant activities. Students are unanimous in connecting the school curriculum to future career activities, as well as to adaptation to society. There is therefore a comparison between what is being done in the present in school, and the value of that for what will be done in the future. It is also noteworthy the awareness of trans-disciplinary themes or transferable skills that are necessary in any area of activity, including information technology skills, citizenship, general culture, knowing foreign languages or being proficient in the mother tongue: "Portuguese is our mother tongue, you have always to express yourself very well in your mother tongue... and of course, English as a foreign language, it's the universal language" (16-year-old boy). Activities with specific formats are also valued, such as team works, study visits or field trips, and project works. As a 17-year-old boy puts it, "Doing projects prepare us... for example to function better in society, they make us more autonomous, and make us deal with others...". Beyond the curriculum domain, the value of extraccuricular activities is also emphasized, either as a way of promoting personal development, or because of the awareness and self-knowledge they provide about personal skills: "School clubs allow us to learn new things. We can also improve our capacities" (15-year-old boy); "These activities fulfill the curriculum... one can learn more stuff to be used in the future" (18-year-old). Students also value the intervention activities provided by psychology and counseling services at school, which give enlightenment about possible educational and career pathways, and opportunity for personal reflection and self-monitoring: "We should have more time for interviews with the counselor" (15-year-old male); “... The sessions with the counselor, in which we can get an idea, that is... we understand things better, we think about us..." (18-year-old female); "We can clarify doubts, and be more prepared for our decisions, in comparison to others that don't have the sessions" (15-year-old female). Finally, one should mention the personal and daily life activities, which were presented as having a clear role in students' prospective thoughts. Some of these activities include, on the one hand, being integrated in community activities (associations, leisure, sports, music), many of them which can be treated as similar to school ones, and, on the other hand, performing daily activities, including contact and observation of professionals, something that may raise awareness of personal preferences. "I'm thinking in choosing kindergarten teacher or something in the social area... I realized that I like that area by dealing with children frequently... I have to take care frequently of my cousins" (18-year-old female); "When I look at adults working, I can see whether I'd be able or like to perform that job" (18-year-old male).

The role of significant others: family, peers, community. Beyond the activities per se, the interpersonal contact with several agents, in part associated to those experiences, also plays an important role in the construction of future perspectives. Among the mentioned agents are teachers, whose role is broader than providing information, and involves also advice, feedback, and modeling. In the adolescents' discourse, teachers' role expresses in several ways: they are one of the first sources of information regarding career opportunities; they provide feedback on students' skills; they give incentive and promote students' awareness about their pathways; they are models, through their behavior and personal stories or remarks; finally, when lecturing, they underline the value that specific contents have for students' future, that is, they mention the instrumental value of present activities for the future. The answers students gave on who can influence their perspectives for the future are clarifying: "Certainly teachers, for example when they say things like "you're good at this or that" (14-year-old male); "I frequently talk to teachers about what I'm going to do with my life. They give their opinion and I appreciate it" (15-year-old male). Another relevant agent in school context is the psychology and counseling services, whose influence is performed through the activities they provide to students, such as career education programs at class or individual level (Carvalho, 2015, in press). Students' family plays as well a relevant role, not only through modeling, but also by providing incentive, encouragement, and even information. Families can also exert a significant power in students' plans and choices through the experiences they provide, since these experiences favor self-knowledge and the definition of goals: "I usually talk to my parents about my future. They help me a lot and incentive my study, by saying that I must pay attention to school because it's going to improve my future. 
They say they have not had the same opportunities that I have, and they want me to take it" (14-year-old female); "I usually talk at home about what I want to do... I say to mom what I want, and she talks about alternatives in order to see whether I like them as well" (17-year-old male); "My parents talk me about a good job... I've mentioned engineering, but we analyzed my grades together, especially in Math, and I guess it will be complicated" (14-year-old male). In the same sense, colleagues and friends arose as important agents influencing both directly and indirectly their future perspectives: respectively, by expressing opinions on specific choices, and by creating informal reflection moments. In the usual contacts that students have with each others, mainly in informal moments such as breaks and free time, they frequently discuss and comment each others' plans for the future: "Yes, sometimes when we're at our breaks together, for example, there in the corner, we start talking about the future and what we're going to do, and each one gives her opinion" (15-year-old female); "We talk a lot about what courses we're going to choose" (14-year-old female). Finally, results show that other's influence transcend the proximal relational circle and involve contexts that are not within the range of family or school control. For instance, the media and daily experiences are pointed out as having influence on students' decisions, for instance through the information they provide about certain occupations. This kind of sources did not appear to be major or decisive influences, but they deserve some attention. “... Well, things I watch on TV programs, even in soap operas!... People I see working, and to whom I pay attention" (14-year-old male); "I thought to choose Arts... I've consulted many works of designers, and I identified myself with their works... I watched a few things on TV and I looked on the internet" (15-year-old male).

\section{Discussion}

With this qualitative study, the identification of emerging issues when students talk about their future, and therefore the creation of an opportunity to characterize in a broader manner their FTPs, was intended. From the obtained results, several aspects are noteworthy. Firstly, it is clear that adolescents, particularly at the end of 9th grade, are concerned and reflect about their future, mostly in an optimistic manner. The individual differences, though, can be found in the quality and degree of elaboration of those perspectives - despite thinking about the future is an activity common to every participant, the way they think and organize the content of their thoughts varies, even when they have an extended view (Lens et al., 2012). Another relevant aspect in the results involves the predominance of career related contents, at the expense of other significant domains (e.g., social relationships, leisure time, and overall development as a person) that are usually prevalent in adolescents' perspectives concerning the future (Marttinen \& Salmela-Aro, 2012). Whilst this result may have been influenced by the fact that students were in school context, and mainly, at the counseling office, when the interviews occurred, some potential explanations can be considered. For instance, such result may represent a frequent exposure to career related themes - since school values significantly the theme of future career -, and also may illustrate the importance students give to ensuring future income by getting a job, particularly when their socioeconomic background is less privileged. Still, since the future is characterized by different relevant domains, which should be all worked on, this potential under-representation of other domains beyond career, must be further analyzed.

Beyond the emphasis on specific domains, it also emerged from students' discourse the value given to present activities and interpersonal contact. For instance, they mentioned the inter-disciplinary subjects such as citizenship, project works, or field trips, as well as the extracurricular activities, which promote the development of skills and interests, and also favor prospective thought. Given that extracurricular and leisure activities are often considered as secondary or merely as a way to occupy students' free time, S2 results suggest otherwise. In the same sense, it was observed a valorization of programs focused in career and personal development, which usually typify psychological and counseling intervention in schools. This shows that not only positive results can be obtained with these programs (Carvalho, 2015, in press), but also that students really value them. In fact, since FTP is a core dimension of career adaptability and significant dimension of vocational choice (Ferrari, Nota, \& Sorei, 2012; Marko \& Savickas, 1998), being related to career maturity (Janeiro, 2010; Janeiro \& Marques, 2010), it should be considered in the framework of vocational development and of the intervention of career services at school. Finally, beyond the expected role of family on adolescents' thoughts about the future, it is noteworthy the influence of teachers and peers, frequently in an informal manner, in the sort of future plans that students develop. In a socioeconomic context characterized by a lack of access to social and cultural resources, and in some cases by family disengagement from students' academic pathways, teachers seem to play an important role (Pinto, Taveira, \& Fernandes, 2003). Moreover, teachers are frequently the first adult who students tend to contact with when they look for information, even when this information is beyond the domain of the teacher's course subject.

Considering FTP theory, results show a relevant aspect of the relationship between present and future: the instrumental value of school activities for the fulfillment of future projects (Lens et al., 2012). In fact, students feel more engaged and driven to learning when they perceive the subject importance or its relation with their future, for instance for their future professional activity. As such, it seems very important to make clear a connection between what is taught, and academic or professional future activities: the more evident is the connection, the greater is students' motivation (Simons et al., 2004). 
The completion of this research, which used both quantitative and qualitative techniques, intended to provide a contribution to the understanding of adolescents' future perspectives in school context. Particularly, there was an interest in the analysis of the present aspects of reality that relate to the way students look at the future. Despite several significant and encouraging results, some limitations and future challenges must be taken into account. In S1, one of these is the necessary future differentiation between present and future oriented factors in QFTP, as well as the replication of the present factorial structure with different samples, for instance through different methods of rotation such as direct oblimin (for correlated variables), leading to a more robust structure, and furthermore, through confirmatory factorial analysis. Also useful, will be future studies of convergent validity using other instruments. Concerning S2, the small and homogenous composition of the sample must be taken into account, as it may have contributed to the findings, even if representativeness is not a concern of qualitative research methodologies. Some effects of social desirability may have existed too, since data collection was performed through individual interviews to voluntary and therefore more interested - students, as well as in the context of the intervention of school counseling services. Certainly, the understanding of the way students elaborate their FTPs requires wider samples and further instruments, from which other relevant themes may emerge. Yet, the emergent themes encourage more attention to the way and to the existing influences on students' representations towards the future when related to the school environment. Despite school is a rather future oriented context, only a thorough analysis and understanding of those aspects will make school's future orientation more effective and meaningful for students.

\section{References}

Bembenutty, H., \& Karabenick, S. A. (2004). Inherent association between academic delay of gratification, future time perspective, and self-regulated learning. Educational Psychology Review, 16(1), 35-57. doi:10.1023/B:EDPR.0000012344.34008.5c

de Bilde, J., Vansteenkiste, M., \& Lens, W. (2011). Understanding the association between future time perspective and self-regulated learning through the lens of self-determination theory. Learning and Instruction, 21(3), 332-344. doi:10.1016/j.learninstruc.2010.03.002

Carvalho, R. G. (in press). Desenvolvimento de projectos na adolescência: Avaliação e perspectivas sobre a intervenção psicológica. Revista Iberoamericana de Diagnóstico y Evaluación/e Avaliação Psicológica.

Carvalho, R. G., \& Novo, R. F. (2012). Family socioeconomic status and student adaptation to school life: Looking beyond grades. Electronic Journal of Research in Educational Research, 10(3), 1209-1221.
Carvalho, R. G., Pocinho, M., \& Silva, C. (2010). Comportamento adaptativo e perspectivação do futuro: Algumas evidências nos contextos da educação e da saúde. Psicologia: Reflexão e Crítica, 23(3), 554-561. doi:10.1590/S0102-79722010000300016

Carvalho, R. G. G. (2012). A personalidade na compreensão do percurso escolar na adolescência (Unpublished doctoral dissertation). Universidade de Lisboa, Lisboa, Portugal.

Ferrari, L., Nota, L., \& Sorei, S. (2012). Evaluation of an intervention to foster time perspective and career decidedness in a group of Italian adolescents. The Career Development Quarterly, 60(1), 82-96. doi:10.1002/j.2161-0045.2012.00007.x

Janeiro, I. N. (2010). Motivational dynamics in the development of career attitudes among adolescents. Journal of Vocational Behavior, 76(2), 170-177. doi:10.1016/j.jvb.2009.12.003

Janeiro, I. N., \& Marques, J. F. (2010). Career coping styles: Differences in career attitudes among secondary school students. International Journal of Educational and Vocational Guidance, 10(1), 35-48. doi:10.1007/s10775-009-9170-3

Lens, W., Paixão, M. P., Herrera, D., \& Grobler, A. (2012). Future time perspective as a motivational variable: Content and extension of future goals affect the quantity and quality of motivation. Japanese Psychological Research, 54(3), 321-333. doi:10.1111/j.1468-5884.2012.00520.x

Lens, W., \& Tsuzuki, M. (2007). The role of motivation and future time perspective in educational and career development. Psychologica, (46), 29-42.

Marko, K. W., \& Savickas, M. L. (1998). Effectiveness of a career time perspective intervention. Journal of Vocational Behavior, 52(1), 106-119. doi:10.1006/jvbe.1996.1566

Marttinen, E., \& Salmela-Aro, K. (2012). Personal goal orientations and subjective well-being of adolescents. Japanese Psychological Research, 54(3), 263-273. doi:10.1111/j.1468-5884.2012.00521.x

Mello, Z. R., Bhadare, D., Fearn, E. J., Galaviz, M. M., Hartmann, E. S., \& Worrell, F. C. (2009). The window, the river, and the novel: Examining adolescents' conceptions of the past, the present, and the future. Adolescence, 44(175), 539-556.

Mello, Z. R., \& Worrell, F. C. (2006). The relationship of time perspective to age, gender, and academic achievement among academically talented adolescents. Journal for the Education of the Gifted, 29(3), 271-289.

Paixão, M. P., \& Silva, J. T. (2001). Estudo do funcionamento motivacional em momentos críticos de tomada de decisão vocacional: Estudo exploratório. Psychologica, 26, 169-179.

Peetsma, T., Hascher, T., van der Veen, I., \& Roede, E. (2005). Relations between adolescents' self-evaluations, time perspectives, motivation for school and their achievement in different countries and at different ages. European Journal of Psychology of Education, 20(3), 209-225. doi:10.1007/BF03173553 
Peetsma, T., \& van der Veen, I. (2011). Relations between the development of future time perspective in three life domains, investment in learning, and academic achievement. Learning and Instruction, 21(3), 481-494. doi:10.1016/j.learninstruc.2010.08.001

Pinto, H. R., Taveira, M. C., \& Fernandes, M. E. (2003). Os professores e o desenvolvimento vocacional dos estudantes. Revista Portuguesa de Educação, 16(1), 37-58.

Savickas, M. L. (2005). The theory and practice of career construction. In S. D. Brown \& R. W. Lent (Eds.), Career development and counseling: Putting theory and research to work (pp. 42-70). Hoboken, NJ: John Wiley \& Sons.

Simons, J., Vansteenkiste, M., Lens, W., \& Lacante, M. (2004). Placing motivation and future time perspective theory in a temporal perspective. Educational Psychology Review, 16(2), 121-139. doi:10.1023/B:EDPR.0000026609.94841.2f

Strauss, A., \& Corbin, J. (1990). Basics of qualitative research: Grounded theory procedures and techniques. Newbury Park, CA: Sage.

Walker, T. L., \& Tracey, T. J. G. (2012). The role of future time perspective in career decision-making. Journal of Vocational Behavior, 81(2), 150-158. doi:10.1016/j.jvb.2012.06.002

Zimbardo, P. G., \& Boyd, J. N. (1999). Putting time in perspective: A valid, reliable individual-differences metric. Journal of Personality and Social Psychology, 77(6), 1271-1288. doi:10.1037/0022-3514.77.6.1271

Renato Gomes Carvalho is an Assistant Professor of the Universidade de Madeira, Portugal.

Received: Aug. 18, 2014

1st Revision: Jan. 13, 2015

2nd Revision: Jan. 19, 2015

Approved: Jan. 29, 2015

How to cite this article:

Carvalho, R. G. (2015). Quantitative and qualitative assessment of adolescents' future time perspectives. Paidéia (Ribeirão Preto), 25(61), 163-172. doi:10.1590/1982-43272561201504 